\title{
Editorial
}

Human Resources has truly come a long way and has arrived in the new millennium in true sense. From the days of early labour management, wage fixation during the industrial revolution way back in mid-19th Century, it transformed itself completely by using cutting-edge technology and true interdisciplinary approach. The change was slow but steady. The change was certain and decisive. Collateral damage happened as enormous job cuts due to consistent evolution of technology took place. The slimming of an organisation has often been viewed as a painful exercise. Green approaches and sustainable developments as an integrated and holistic manner is the new buzzword in the world of HR. Analytics and AI (Artificial Intelligence) are playing major roles. Bio data was earlier replaced by sophisticated Curriculum Vitae. Even that seems to be an outdated process today. Companies are tracking and choosing prospective employees as well as existing employees through their social (or digital) footprints in Facebook, Whatsapp, and Twitter. HR has invented a whole new way of reward by transforming money-driven rewards systems. It's recognition that excites people nowadays. Continuous motivation is the key in this fast paced and competitive world. HR, sometimes help their employees to stay ahead in this rat-race by a unique way of providing constant motivation. This issue has a Book Review of "Not just for the Money - Bruno S Frey" by Kaushani Mazumder and Diksha Singh that emphasises the importance of other important factors of workplace motivation.

Trade Unionism and compensation dynamics have changed dramatically. With the advent of socio-capitalism, replacing communism in eastern European blocks, Cuba and Russia, the fate and face of Human Resources practices as well as beliefs have changed. The article Trade Unionism and Compensation Dynamics: A Research Overview by Indranil Bose and Baisakhi Mitra Mustaphi enlightens our perspectives in this regard.

HR constantly involves itself with rural entrepreneurship, social entrepreneurship and upliftment of the neglected part of the society. Involving and engaging society is no longer a public 
relation practice in a caged environment. The new age management focuses on extending boundaries. A Study on Empowerment Quotient of Women in Agriculture Sector - An Empirical Study by Hema Srinivasan provides her perspective on the womenentrepreneurship in various diverse parts of rural India in the quest gender equality.

In an article titled, Share Price Analysis for Selected Companies based on Human Resource Practices, Corlise Liesl Le Roux investigates the close interconnectedness between HR, Finance and investments. Comparing across different performance indices, the paper analyses the financial performance of 12 top ranking and 12 bottom ranking companies based on their year percentage change and $\mathrm{P} / \mathrm{E}$ ratio.

Interestingly financial parameters are found to be more efficient for companies with better and effective HR policies and practices. It's a challenge to keep recruiting, training and motivating a multicultural and heterogenetic group connected by an enormously brittle social media network. In the article, Detailed Literature Review: Antecedents Affecting the Flight Risk or Turnover Intention of Professionals by Archana Singh we will find observations and analyses of the effectiveness of better HR policies (Workforce 100 Companies) in financial performance with reference to the growth of the company.

It gives me immense pleasure to bring forth this issue of Ushus Journal (on HR themes and practices) that allows further thoughts to grip our minds and provides avenues for further research in the following direction. End of the day, it's an endless journey that appears to be a straight line, despite being the part of a massive circle.

\section{Bikramaditya Ghosh}

Issue Editor 